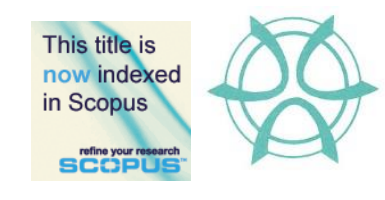

PLANNING MALAYSIA:

Journal of the Malaysian Institute of Planners

VOLUME 16 ISSUE 3 (2018) Page 285 - 296

\title{
NCIA-AMB MASUK KAMPUNG PROJECT: A PARADIGM OF OPPORTUNITIES AND CHALLENGES FOR SUSTAINABLE RURAL DEVELOPMENT
}

\author{
Sana Malik ${ }^{1}$, Faiqa Khilat ${ }^{2}$, Fariha Tariq ${ }^{3}$, \& Kamal Arifin ${ }^{4}$ \\ ${ }^{1}$ School of Housing, Building \& Planning \\ UNIVERSITI SAINS MALAYSIA \\ ${ }^{2,3}$ School of Architecture \& Planning, \\ UNIVERSITY OF MANAGEMENT \& TECHNOLOGY, PAKISTAN \\ ${ }^{4}$ Prlma Homes \\ PERBADANAN PR1MA MALAYSIA, MALAYSIA
}

\begin{abstract}
Malaysian government is focused to accomplish world-class living standard of whole nation by year 2025 through sustainable development irrespective of regional, religious and ethnic boundaries. The Northern Corridor Implementation Authority (NCIA) is an organization set up for the implementation of Koridor Utara (Northern Corridor Economic Region, NCER) in Malaysia for achieving this vision. Such economic corridors are aimed to elevate the income levels through agriculture, manufacturing, logistics, education and tourism. The execution of development projects always impact the involved community in multiple dimensions. Masuk Kampung Project at Pantai Murni, Yan Kedah was one of the NCIA initiatives in collaboration with AMB (Akademi Binaan Malaysia). This paper draws out a conceptual framework of community perceptions associated with this project based on qualitative research. Viewpoints studied through interviews and participant observation helped in fabricating the opportunities and challenges connected with rural development. Findings revealed that community perception is of key importance and their prime reflections can be beneficial to policy makers, stakeholders, academicians and civil society in shaping the policy agenda for future projects of same nature in Malaysia. Hence, the study is a contribution to understanding development projects aiming at rural areas on national and global channels.
\end{abstract}

Keywords: sustainability, rural development, economic conditions, sustainable tourism, community perceptions 
Sana Malik, Faiqa Khilat, Fariha Tariq, \& Kamal Arifin

NCIA-AMB Masuk Kampung Project: A Paradigm of Opportunities and Challenges for Sustainable Rural Development

\section{INTRODUCTION}

Malaysia is a multi-ethnic and multi-religious country with a population of 28.5 million. It is characterized by three main ethnic groups: Malay and indigenous people, Chinese, and Indians. Ever since the independence from the long British rule in 1957, Malaysia has successfully transformed itself from a poor country into a middle-income nation by stressing on the economic development of rural areas in its five-year plans (Hatta \& Ali, 2013). Many schemes were introduced to encourage development of agriculture sector, rural industrialization, resettlement schemes, infrastructure, and community development. This has been observed to be a continuous process, aimed to achieve certain, carefully crafted goals and solve root-level problems faced by rural community. Due to the exceptional nature of rural development plans, with prominent state interventions, rural development in Malaysia is now considered to be identical with state's development strategies. Such plans are aimed to solve problems such as the sharp contrast between the lifestyles in the urban and rural areas, deficiency of financial growth, inadequate rural that prevailed prior to independence and little productivity. In this regard, Northern Corridor Implementation Authority (NCIA) is an authorized organization for the execution of one such project named as Northern Corridor Economic Region (NCER) in Malaysia. However, recent study discovered that accomplishments from the project have not visualized the expectation; hence leading to poor execution of NCIA which was meant to operate in flexible manner to achieve the overarching goal of shared growth while ensuring compliance from all stakeholders (Athukorala \& Narayanan, 2018). This sets the direction to study the concerns of one of the stakeholders involved i.e. the community, for successful implementation and execution of such projects. Zal (2018) established that it is important to determine the right group of people from which to gain information about a community's potential, and also the need, as a first step, to involve both groups of people in the development process. The current study revolves around one of NCIA rural project in collaboration with AMB (Akademi Binaan Malaysia) in Pantai Murni, Yan, Kedah within the framework of such project. Discussions focused on the opportunities and challenges associated with sustainable rural development from the viewpoint of kampung (village) community. The study holds significance by observing the kampung perceptions in relation to the actual facts of rural economic progress in Malaysia.

\section{THEORETICAL FRAMEWORK}

In order to meet vital energy needs economically, efficiently and sustainably of present world, a balanced energy portfolio is required. The portfolio should be well-suited for the socio-economic conditions of the country as well as for its own region on individual basis. Roughly 1.6 billion people worldwide do not have access to electricity in their homes, representing slightly more than one quarter 
PLANNING MALAYSIA

Journal of the Malaysia Institute of Planners (2018)

of the world's population (Flavin \& Aeck, 2005). In many areas, people still live without refrigeration, television/radios, and even light. The investment of energy resources in rural areas is a core step in achieving economic sustainable development.

Sustainable development is generally discussed in terms of environmental considerations, but from a rural community perspective, sustainable development must address how people of the community generate the income to maintain their rural lifestyle (Freshwater, 2000). Sustainability ensures that generated benefits and supported organizations meant to continue even after the completion of project. Sustainability is defined as guarantee that the institutions supported through projects and the benefits realized are maintained and continue after the end of the project (Tango International, 2009).

There are many scholarly approaches to rural development. According to (Maxwell, Urey, \& Ashley, 2001), "In peri-urban zones, the main opportunities are likely to include intensive agricultural activities for the city, short-distance commuting, weekend leisure, and town-oriented industrialization; further away from towns, arable farming, some tourism, and resource-based industrialization are options; in remote areas, subsistence farming, long-distance migration and 'niche' tourism are likely to be the main options". This viewpoint describes distance of rural areas from cities as major factor for measuring the potential of rural development projects. Another stance relates to the evolving of rural development over the years as symbiotic feature. Ellis (2000) illustrated this evolution from basic community development to integrated rural development, which has got further attention as sustainable livelihoods providing solution to poverty eradication for more than two decades.

Malaysia has well incorporated such sustainable approaches of rural development in its national plans. According to Grand Transformation Plan (GTP), the accessibility of basic infrastructure is stated as a primary right of every resident of Malaysia irrespective of their location. State and local governments are promised to provide four major components of national infrastructure namely roads, electricity, water and housing to cater some percentage out of 35\% Malaysian rural community (Prime Minister's Department, 2010). Several studies have been conducted on the rural developments and its multidisciplinary scopes opened venues for different philosophical discussions. In this regard, study on the ideological context of rural development in Sabah, Malaysia revealed that such development works provide the entry point for federal government into village politics; if development does not necessarily raise the local standard of living, it facilitates the expansion and entrenchment of the ruling elite - the United Malaysia National Organization (UMNO) (Doolittle, 2014). Recently, another study in three rural villages of Perak State was conducted to discover the viewpoints of rural community about the renewable energy technologies aiming to advance sustainable lifestyles in rural setting. Findings suggested that even due 
Sana Malik, Faiqa Khilat, Fariha Tariq, \& Kamal Arifin

NCIA-AMB Masuk Kampung Project: A Paradigm of Opportunities and Challenges for Sustainable Rural Development

to limited understanding of village folks, state-funded information and management programs about perks and benefits of renewable technology will extend the usage of low-carbon technological impacts within Malaysian rural setup (Sivapalan, Haunschmid, \& Isa, 2017). Building upon dedicated momentum of rural development, $10^{\text {th }}$ Malaysian Plan integrated economic corridors as a key element of the country's economic strategy, as well as a means to tackle "intraand inter-regional imbalances" narrowing down to only or two lead respective sectors (Hutchinson, 2017)

\section{PROJECT FRAMEWORK AND RESEARCH METHODOLOGY}

\section{Brief Description of NCIA-AMB Project}

Vision of Koridor Utara (NCER) states: "To be a world-class economic region of choice for investments, work, living and learning in a safe, clean and sustainable environment by 2025" (Northern Corridor Implementation Authority, 2012).The Government of Malaysia is striving for establishment of socio-economic oriented projects to achieve remarkable progress of rural areas of the country. NCIA is responsible for developing the Koridor Utara (NCER) which includes four states of Malaysia i.e. Perlis, Kedah, Penang and Northern region of Perak. The objective is to upgrade living standard in the region economically and socially by year 2025 as stated earlier. NCIA-AMB Masuk Kampung Project in Pantai Murni, Yan Kedah was one of such development schemes (Figure 1). The theme of project was structured on economic development through automotive \& aeronautics sectors and tourism development (Hutchinson, 2017). The expectations can be better realized by approaching kampung folks during and after the execution phase of project to discover their perspectives and ideologies. The purpose of this study is to understand the thin line between anticipations and actual impacts and experiences of kampung community as consequence of this project. Such perceptual framework is essential for drawing out environmental impact studies and future policies for rural development projects.

\section{Research Methodology}

Perceptions of kampung community were recorded through qualitative research methods comprising semi-structured interviews and participant observation. This combination of qualitative research was essential to document the perceptions and viewpoints of rural community of the project. The purpose of such methods permits the generation of facts and figures from multiple sources of information. This provides platform for broad understanding of research concerns.

Primary qualitative data was composed at kampung level through semistructured interviews based on multiple themes of sustainable development including economic sustainability, tourism development, improvement of infrastructure, exposure of local culture, loss of forest cover, transformation of 
PLANNING MALAYSIA

Journal of the Malaysia Institute of Planners (2018)

rural environment into urban, negative impact on marine life, and inflation of land prices. The interview session involved 10 families randomly selected from the kampung community in the summer of 2014. Interviewees were asked to express their hidden concerns and thoughts about ongoing construction of project. The respondents were stimulated to speak freely on the established themes of discussion regarding the perceived challenges and opportunities associated with NCIA-AMB Kampong project. Also, exercise of participant observation further strengthened the discussion points highlighted by respondents involved in the study. Primary data was further complemented with secondary data through existing literature to justify the documented perceptions of community.

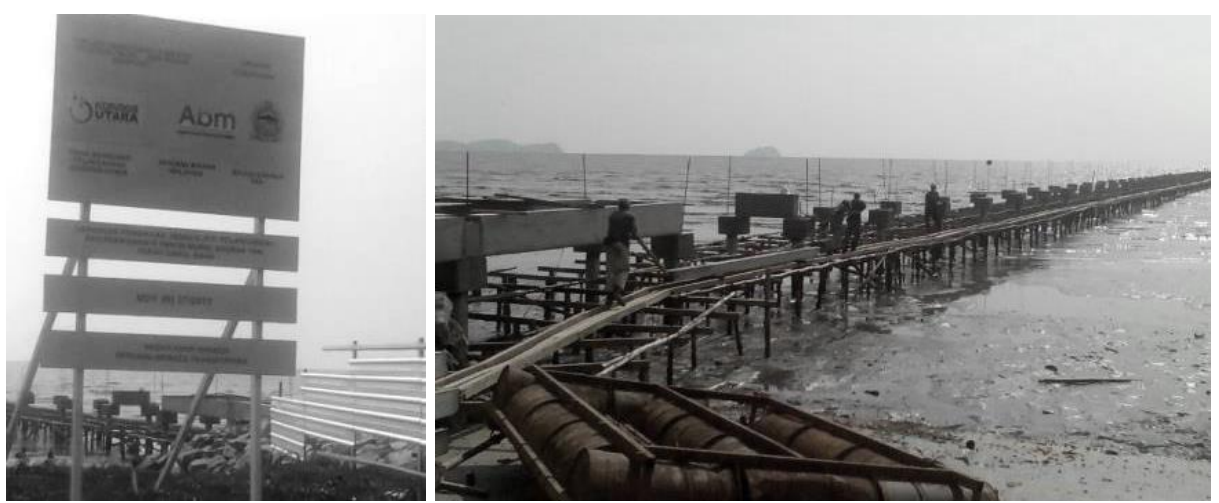

Figure 1: Execution stage of NCIA-AMB Kampung Project

Source: Author

\section{RESULTS \& DISCUSSION}

\section{Economic Sustainability}

Under the influence of globalization concepts and changing trends, the community are looking forward to the generation of variety of business and trading opportunities (Derek Hall \& Mitchell, 2005). This is also true in case of NCIA-Kampong project, Yan, Kedah. As told by one of the interviewees, expectations included better movement of human capital for different types of business and commercial opportunities. The economic altitudes of rural families are projected in order to increase living standards and poverty eradication (UNDESA, 2012). Previous development projects in all 5-year Malaysia Plans have shown promising consequences for raising income levels of rural community (Table 1). 
Sana Malik, Faiqa Khilat, Fariha Tariq, \& Kamal Arifin

NCIA-AMB Masuk Kampung Project: A Paradigm of Opportunities and Challenges for Sustainable Rural Development

Table 1: Reduction in poverty in urban and rural Malaysia

\begin{tabular}{lcccc}
\hline & 1970 & 1992 & 2002 & 2012 \\
\hline URBAN & $21.3 \%$ & $4.7 \%$ & $2.3 \%$ & $1.0 \%$ \\
RURAL & $58.7 \%$ & $21.2 \%$ & $13.5 \%$ & $3.4 \%$ \\
\hline
\end{tabular}

Source: Elhadary \& Samat (2015)

For instance, after upgrading of connecting bridge called White Elephant Bridge, between Pulau Bunting and Pantai Murni in Yan, Kedah, noticeable increase in activities of economic and social sectors leading to better employment opportunities was exposed as key forecast by the community. The Kedah government plans to develop Pulau Bunting as a port. Since the NCIA-AMB project is aimed at the economic development of region, rural community was observed to be curious about the business opportunities after the project completion. Before the completion of the project the employing activities to earn monthly income was majorly fishing as explained by one of the kampung folks. No doubt, demand for increased income opportunities is always there due to continuous population growth; indicating economic sustainability of rural projects through constant availability of social capital.

\section{Tourism Development}

Internationally tourism development of rural areas is considered to be a major factor that affects the areas socially, economically and culturally, giving it a prime consideration for a sustainable development (Donald \& MacLeod, 2010). It benefits in the promotion of art and culture of the area involving different strategies and many governments encourage tourism development as it add up to their economy (Lee, Lee, Yongseok Shin, \& Wall, 2016). Malaysia five-year development plans included rural tourism as one of the integral development strategy for achieving economic stability in rural areas. An increasing number of communities have started their own homestay programs, which offer holiday experience in rural setting (Kayat \& Mohd Nor, 2006). These programs are mostly operated by local communities and require local involvements. The project of NCIB-ABM Masuk Kampung followed the same trend to enhance investment in the tourism development through local and international tourists. Before the commencement of the project, in viewpoint of kampung public, tourism was imagined to bring the diverse social groups to Kampung Pantai Murni. This encouraged the community to invest at the location along with concept of homestay program for the promotion of rural tourism. Local public in kampung desired to operate such types of program to get themselves involve in implementing sustainable development of tourism. However, this sector still demands the skills among rural communities necessary for running, managing, and promoting a tourist product (Marzuki, Ali, \& Othman, 2010). 
PLANNING MALAYSIA

Journal of the Malaysia Institute of Planners (2018)

\section{Improvement of Infrastructure}

The Malaysian perspective is described in Government Transformation Program (GTP) that all nationals of Malaysia, regardless of their ethnicity and location, will receive good lifestyle. According to this viewpoint, the wide provision of improved infrastructure was one of major expectations of whole community (Figure 2). Electricity is beneficial in terms of new opportunities of work, domestic, household, educational and leisure benefits (Torero, 2014). In addition to electricity, provision of water facility is also key factor for adequate infrastructure. It is evident from previous rural development projects (19802005), there was 50\% increase in households with piped water connections attaining figure of $90 \%$ where the only exception were states of Sabah and Kelantan achieving $60 \%$ of rural households with piped water provision. Taking expression on the supply of electricity to rural and urban areas during 1992 2000, Ngah (2010) confirmed that in year 2000 the families having electricity in East Malaysia were more than 90\% in Sarawak and 70\% in Sabah.

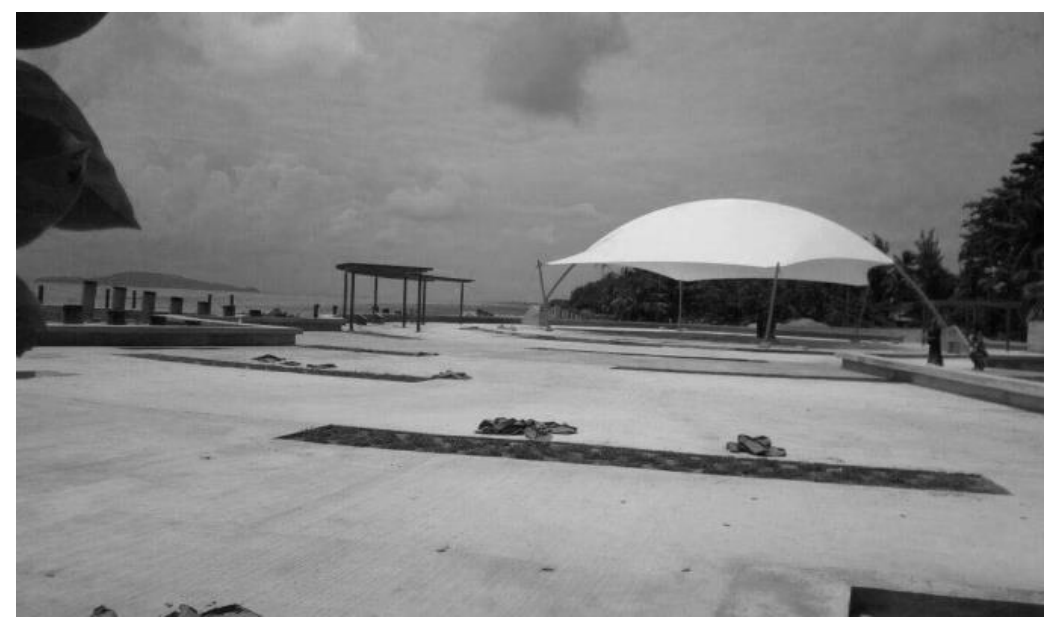

Figure 2: View of NCIA-AMB Project after completion

Source: Author

\section{Exposure of Local Culture}

The influx of foreigners into the rural setting makes a great contribution of exposing local culture to global channel. Mixed responses from kampung folks were observed for this concern perceiving it as an opportunity and challenge. The positives argued that this would attract more foreign tourists and that they will return home with the experience, local cuisines and dresses, as well as other local souvenirs purchased. On the contrary, the negatives supported the conventional perspective of influx of foreign tourists would lead to local culture losing originality of character. 
Sana Malik, Faiqa Khilat, Fariha Tariq, \& Kamal Arifin

NCIA-AMB Masuk Kampung Project: A Paradigm of Opportunities and Challenges for Sustainable Rural Development

\section{Loss of Forest Cover}

Forest cover and green lands are the prime assets of rural community of Malaysia. The proposed projects adversely impacting the green environment. Construction phase is more focused on removing the green cover instead of utilizing them in a healthy way for environmental sustainability as the planned framework of the projects demand more cutting of trees and concreting the land (Figure 3). During the execution phase, the natural touch of rural setting got affected through demolishing of traditional Malay houses. Gradual increase of temperature and gradual decrease of green environment were recorded as prime concerns according to kampung folks. Due to constructed bridge, the natural resources got disturbed to some extent. The venture of energy sources in the area created a little discomfort among kampung folks due to loss of forest cover.

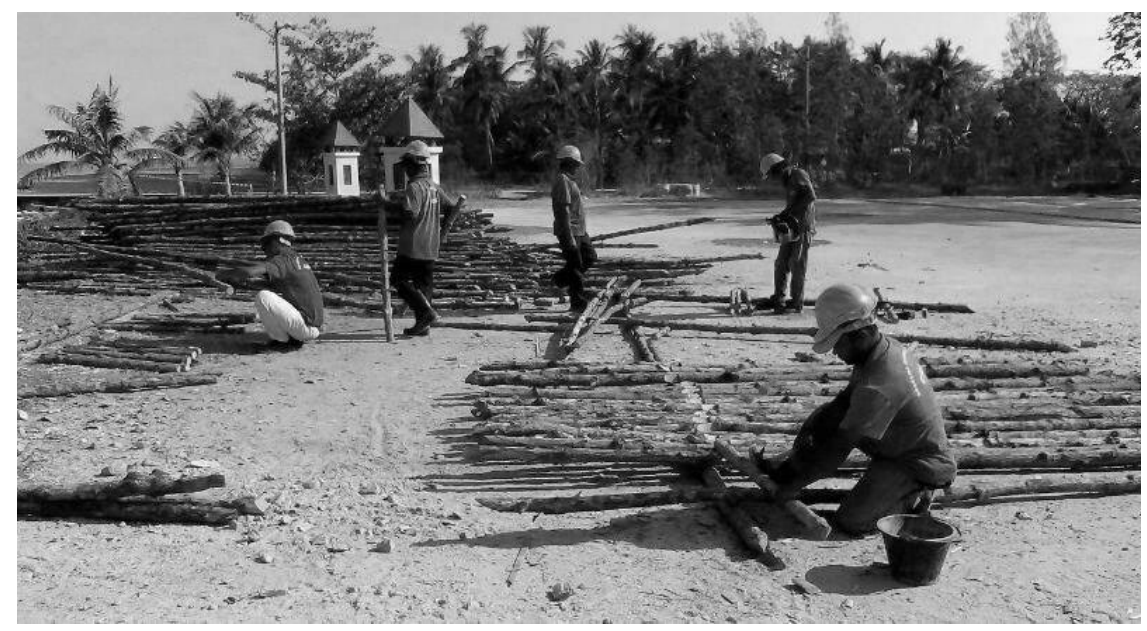

Figure 3: View of on-site construction works Source: Author

\section{Transformation of Rural Environment into Urban}

The transformation of rural setting into urban setting is accompanied by environmental cost putting natural resources at stake. Concrete structures and covered land surface are consuming the rural look and setting as described by one of the kampung folks. Another perception can be argued here that limitation on extension of agricultural and farming production in the area can account for shortage of local employment opportunities. Kampung people believed that the changed face of rural setting with constructed bridge is associated with more business opportunities. The rural-urban division is somehow disappeared after the complete execution of the project, bursting as a great concern for the kampung folks (Figure 4). Restricted dispersion of water into the sea in heavy rainy seasons due to these manmade structures, which become cause of flooding lately, was documented as prime reason behind this concern. 


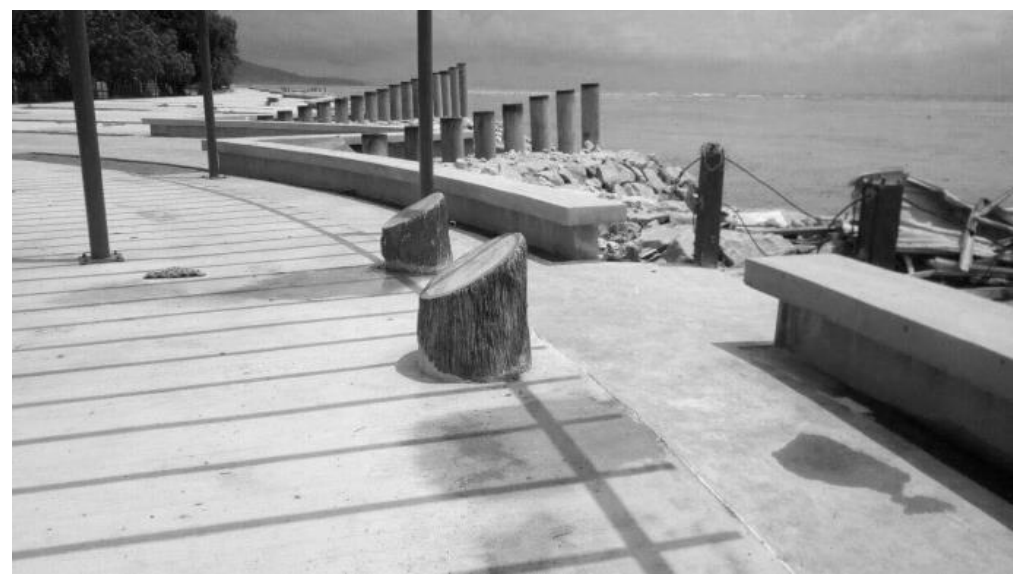

Figure 4: Transformed outlook of the kampung Source: Author

\section{Negative Impact on Marine Life}

Development projects tend to impact the natural environment due to human and mechanical activities involved in a construction project. NCIA- AMB Masuk Kampung project affected the marine environment and contributed to water pollution. In fact, this is a critical consequence as recent study established that despite vast development in Malaysia, there is a myriad of water shortage issues; the country needs to carefully manage its freshwater resources to achieve sustainable development (Oh, Leong, Poh, Chong, \& Lau, 2018). One of the kampung representatives described that due to newly introduced commercial activities heaps of garbage and excessive amount of wastes went into the sea. In this regard, one such project named Crocker Range National Park (CRNP) was initiated in 1984 to save the biodiversity of the forest and preservation of water with its safe distribution. Later, the government opened it for tourists which adversely affected the natural habitat, resulting into loss of diverse variety of flora and fauna due to human activities (Hjulmand, Nielsen, Vesterløkke, Busk, \& Erichsen, 2003). Such negative impact is a great challenge for achieving sustainable nature of the project.

\section{Inflation of Land Prices}

The Tenth Malaysia Plan 2011-2015 emphasized on economic development of the nation for next five years by connecting rural areas to urban clusters through modern infrastructure and facilities. Likewise, 11th Malaysia Plan 2016-2020 is committed on encouraging more private investment, improving rural-urban linkages, expanding implementation of programs under 21st Century Village, promoting use of modern technologies, empowering rural entrepreneur community, encouraging community driven cooperatives, providing quality rural 
Sana Malik, Faiqa Khilat, Fariha Tariq, \& Kamal Arifin

NCIA-AMB Masuk Kampung Project: A Paradigm of Opportunities and Challenges for Sustainable Rural Development

basic infrastructure and basic services (EPU, 2015). The NCIA-AMB Masuk Kampung Project has similar vision for upgrading the living standard of kampung community by providing amenities, communication and links to the neighbouring urban centres. The fresh investment for tourism purposes in the region has increased the land prices, creating an alarming situation for community in maintaining their homes in the near future. The conversion of adjacent land areas into commercial use within the premises of new development pushed back the existing settlements. This emerged as one of the great concerns for kampung folks. Commercial development encourages inflated rates of land due to provision of modern and up-to-date infrastructure leading to commercialism. This aspect considered as both opportunity for investors and challenge for kampung community at the same time.

\section{CONCLUSION}

The study established that there is need to improve the management and execution phase of development projects for rural areas in Malaysia. Similarly, the aims and activities of such projects should be designed to facilitate the life of rural community and to deal better with their social and environmental issues. This study was dedicated to explore the viewpoints of rural people affected by the NCIA-AMB Masuk Kampung Project (Table 2). Discussions show that improved economic activities, tourism development and upgraded infrastructure were considered as opportunities in viewpoint of rural community. While loss of forest cover, transformation of rural environment into urban and negative impact on marine life were recorded as challenges. Exposure of local culture and inflation of land prices were perceived as both opportunity and challenge by kampung people.

Table 2: Opportunities and challenges involved in NCIA-AMB Project

\begin{tabular}{|c|c|c|}
\hline $\begin{array}{l}\text { Kampung Concerns for } \\
\text { NCIA-AMB project }\end{array}$ & Opportunity & Challenge \\
\hline Economic sustainability & $\sqrt{ }$ & \\
\hline Tourism development & $\sqrt{ }$ & \\
\hline $\begin{array}{l}\text { Improvement of } \\
\text { infrastructure }\end{array}$ & $\sqrt{ }$ & \\
\hline Exposure of local culture & $\sqrt{ }$ & $\sqrt{ }$ \\
\hline Loss of forest cover & & $\sqrt{ }$ \\
\hline $\begin{array}{l}\text { Transformation of rural } \\
\text { environment into urban }\end{array}$ & & $\sqrt{ }$ \\
\hline $\begin{array}{l}\text { Negative impact on marine } \\
\text { life }\end{array}$ & & $\sqrt{ }$ \\
\hline Inflation of land prices & $\sqrt{ }$ & $\sqrt{ }$ \\
\hline
\end{tabular}


This study concludes that these opportunities and challenges should be acknowledged in order to achieve sustainable nature of the rural development project. No doubt, improvement of rural-urban divide will elevate the living standard of rural community, but there is also need to satisfy what people think and feel. State and local governments must admit the vital importance of public participation and perception. This calls for resolving the institutional barriers which prohibit the practice of public engagement in project development process. Since Malaysia is focused in achieving its rural development goals for Vision 2025, incorporating rural community perceptions will help in establishing sustainable nature of rural development projects despite the mandatory mechanical processes and excessive commercialism.

\section{ACKNOWLEDGMENT}

We acknowledge the cooperation of kampung community for expressing sincere views in conducting this research.

\section{REFERENCES}

Athukorala, P., \& Narayanan, S. (2018). Economic corridors and regional development: The Malaysian experience. World Development, 106, 1-14.

Derek Hall, I. K., \& Mitchell, M. (2005). Rural tourism and sustainable business. Bristol, UK: Channel View Publications Ltd.

Donald, V. L., \& MacLeod, S. A. (2010). Sustainable tourism in rural Europe: Approaches to development. London: Taylor \& Francis.

Doolittle, A. A. (2014). Are they making fun of us? The politics of development in Sabah, Malaysia. France, Europe: Presses Universitaires de Provence.

Elhadary, Y., \& Samat, N. (2015). Malaysia towards zero poverty by 2020. Proceedings of the International Conference on Development and Socio Spatial Inequalities 2015. Penang: USM Press.

Ellis, F. (2000). Livelihoods and rural poverty reduction in developing countries. Oxford: Oxford University Press.

Economic Planning Unit [EPU] (2015). Transforming rural areas to uplift wellbeing of rural communities. Putrajaya: Author.

Flavin, C., \& Aeck, M. H. (2005). Energy for development - The potential role of renewable energy in meeting the millennium development goals. Washington DC: Worldwatch Institute.

Freshwater, D. (2000). Three parers on rural development. Potsdam: TVA Rural Studies Program.

Hatta, Z. A., \& Ali, I. (2013). Poverty reduction policies in Malaysia: Trends, strategies and challenges. Asian Culture and History, 5(2), 48-56.

Hjulmand, L. G., Nielsen, U., Vesterløkke, P., Busk, R. J., \& Erichsen, E. (2003). Tourism as a development strategy in rural areas adjacent to the Croker Range National Park, Sabah, Malaysia. ASEAN Review of Biodiversity and Environmental Conservation (ARBEC), 1-19.

Hutchinson, F. E. (2017). Evolving paradigms in Malaysia's regional development policy. Journal of Southeast Asian Economies, 34(3), 462-487. 
Sana Malik, Faiqa Khilat, Fariha Tariq, \& Kamal Arifin

NCIA-AMB Masuk Kampung Project: A Paradigm of Opportunities and Challenges for Sustainable Rural Development

Kayat, K., \& Mohd Nor, N. A. (2006). Community members involvement in community development programme: Homestay programme in Kedah. Akademika, 67(1), 77-102.

Lee, A. H. J., Lee, D. B. H., Yongseok Shin, \& Wall, G. (2016). Creativity and Traditional Cultural Accommodations in Sustainable Community Development: The Case of 'Hanok-stay' Program in South Korea. Journal of Rural and Community Development, 11(1), 16-29.

Marzuki, A., Ali, K., \& Othman, A. G. (2010). A review on rural tourism development in Malaysia. International Journal of Hospitality \& Tourism Systems, 3(1), 23-30.

Maxwell, S., Urey, I., \& Ashley, C. (2001). Emerging issues in rural development. London: Overseas Development Institute.

Ngah, I. (2010). Rural development in Malaysia. Kuala Lumpur: Universiti Teknologi Malaysia.

Northern Corridor Implementation Authority. (2012). Koridor Utara Malaysia. Pulau Pinang: Author.

Oh, K. S., Leong, J. C., Poh, P. E., Chong, M. N., \& Lau, E. V. (2018). A review of greywater recycling related issues: Challenges and future prospects in Malaysia. Journal of Cleaner Production, 171, 17-29.

Prime Minister's Department Malaysia (2010). Government transformation programme. Putrajaya: Performance Management and Delivery Unit (PEMANDU).

Sivapalan, S., Haunschmid, S., \& Isa, M. H. (2017). Potential of renewable energy technologies and its implications for the management of low carbon lifestyles in Rural Malaysia. Global Business \& Management Research, , 9, 622-631.

Tango International (2009). Sustainability of rural development projects-Best practices and lessons learned by IFAD in Asia. Tucson-Arizona: International Fund for Agricultural Development (IFAD) IFAD.

Torero, M. (2014, December). The impact of rural electrification. 11th Conference AFD PROPARCO/EUDN: Energy for Development. December 3, 2014, Paris, France.

UN-DESA (2012). Finance for the transition to a green economy in the context of sustainable development and poverty eradication. RIO 2012 Issues Briefs, 16.

Zal, W. A. (2018). The practice of community potential mapping as a guideline for community development in Malaysia. Community Development Journal, 53(2), 321-339. 